\title{
RUANG KREATIF CIPINANG
}

\author{
Bagus Putra Wicaksono ${ }^{1)}$, Mieke Choandi ${ }^{2)}$
}

1) Program Studi S1 Arsitektur, Fakultas Teknik, Universitas Tarumanagara, bagusp026@gmail.com

2) Program Studi S1 Arsitektur, Fakultas Teknik, Universitas Tarumanagara, mieke@untar.ac.id

\begin{abstract}
Abstrak
Stres adalah suatu respon adaptif, melalui karakteristik individu dan atau proses psikologis secara langsung terhadap tindakan, situasi dan kejadian eksternal yang bersangkutan. Stres juga merupakan kondisi dinamis dimana seorang individu dihadapkan dengan kesempatan, keterbatasan atau tuntutan yang tidak sesuai dengan harapan yang ingin dicapai dalam kondisi penting dan tidak menentu (Febriandini, et al. 2016). Stres kerja pada umumnya dipicu oleh faktor individu dan faktor lingkungan. Indonesia tercatat sebagai penduduk yang mengalami stres dimana tingkat stres tersebut dapat meningkat jika tidak diatasi. Adanya faktor stres dari penghasilan yang rendah, dan taraf kehidupan yang tinggi. Oleh sebab itu perlu ada ruang sebagai tempat interaksi bagi seluruh kelas sosial masyarakat dan dapat menjalin perekonomian masyarakat yang baik.
\end{abstract}

\section{Kata kunci: Indonesia; perekonomian; stres}

\begin{abstract}
Stress is an adaptive response, through individual characteristics and / or psychological processes directly to the actions, situations and external events concerned. Stress is also a dynamic condition where an individual is faced with opportunities, limitations or demands that are not in accordance with the expectations to be achieved in important and uncertain conditions (Febriandini, et al. 2016). Job stress is generally triggered by individual factors and environmental factors. Indonesia is listed as a stressed population where the stress level can increase if not addressed. The existence of stress factors from low income, and high standard of living. Therefore there needs to be space as a place of interaction for all social classes of society and can establish a good community economy.
\end{abstract}

Keywords: Indonesian; economy; stress

\section{PENDAHULUAN}

Stres merupakan suatu respon adaptif, melalui karakteristik individu dan atau proses psikologis secara langsung terhadap tindakan, situasi dan kejadian eksternal yang bersangkutan. Stres juga merupakan kondisi dinamis dimana seorang individu dihadapkan dengan kesempatan, keterbatasan atau tuntutan yang tidak sesuai dengan harapan yang ingin dicapai dalam kondisi penting dan tidak menentu (Febriandini, et al. 2016). Stres kerja pada umumnya dipicu oleh faktor individu dan faktor lingkungan.

Ekonomi kreatif memiliki peran penting dalam perekonomian. Salah satunya bisa dilihat dari peningkatan Product Domestic Bruto (PDB) ekonomi kreatif tahun 2014 sebesar 784,82 Triliun meningkat menjadi 852,24 Triliun pada tahun 2015, artinya PDB tumbuh sebesar 4,38\% pada tahun 2015. Ekonomi kreatif memberikan kontribusi sebesar 7,38 persen terhadap total perekonomian nasional. Ekonomi kreatif digerakkan oleh sektor industri yang disebut Industri Kreatif (Departemen Perdagangan RI, 2008).

Berdasarkan data World Health Organization (WHO), sekitar 450 juta orang di Dunia mengalami stres. Untuk di Indonesia tercatat sekitar $10 \%$ dari total penduduk Indonesia yang mengalam stres. Data Riset Kesehatan Dasar (Riskesdas), pada tahun 2013 menyebutkan bahwa sekitar 1,33 juta penduduk DKI Jakarta mengalami stres dimana angka tersebut mencapai 14\% 
dari total penduduk dengan tingkat stres akut mencapai 1-3\% dan stres berat mencapai 7- 10\%. (Perwitasari, et al. 2015).

Berdasarkan Riset Kesehatan Dasar (Riskesdas) 2013 menunjukkan prevalensi gangguan jiwa berat di Indonesia sebesar 1,7 per mil penduduk dan gangguan mental emosional 6,0 \% penduduk. Sedangkan, data Provinsi DKI Jakarta yang disajikan oleh Badan Litbangkes Kemenkes 2013 dalam bukunya Riset Kesehatan Dasar dalam Angka Provinsi DKI Jakarta menunjukkan prevalensi gangguan jiwa berat di ibu kota negara itu sebesar 1,1 per mil.

Kota Jakarta Timur menduduki peringkat tertinggi, yaitu 2,2 per mil, disusul Kepulauan Seribu 1,5 per mil, Jakarta Utara 1,2 per mil, Jakarta Barat 1,0 per mil, Jakarta Selatan 0,2 per mil dan Jakarta Pusat 0,0 per mil. Sedangkan gangguan mental emosional prevalensinya 4,4 \%. Jakarta Timur menduduki peringkat paling tinggi gangguan mental emosional di atas dari prevalensi Provinsi DKI yaitu 6,4 \%, disusul Kepulauan Selatan 4,5\%, Jakarta Utara 4,1 \%, Jakarta Pusat 3,4 \%, Jakarta Barat 2,7 \%, dan Kepulauan Seribu 1,0 \%. Data menunjukkan Jakarta salah satu kota memiliki tantangan pengelolaan gangguan mental emosional, 4,4 persen.

Gubernur DKI, Anies Baswedan membuka Musyawarah Perencanaan Pembangunan (Musrenbang) Kota Administrasi Jakarta Timur di Kantor Walikota Jakarta Timur, Kamis (28/3/2019). Dalam kesempatan ini Anies menekankan bahwa pembangunan harus fokus pada peningkatan ekonomi. Pada Musrenbang di Jakarta Timur ini, Anies Baswedan menekankan sangat dibutuhkannya penerapan konsep pembangunan berkualitas untuk di Provinsi DKI Jakarta. Karena itu, ia meminta seluruh kegiatan pembangunan daerah yang direncanakan, harus mampu meningkatkan angka pertumbuhan, dan kualitas kehidupan masyarakat.

Untuk mencapai tujuan itu, maka ia menginstruksikan agar program pembangunan yang disusun dalam Musrenbang di Jakarta Timur harus berfokus pada pembangunan ruang ketiga. Sebagai tempat interaksi seluruh lapisan kelas sosial ekonomi warga dan juga pembangunan infrastruktur yang mengutamakan pejalan kaki. "Kita ingin bangun ruang ketiga yang dirancang untuk membuat interaksi lintas kelas sosial-ekonomi. Saya berharap, nantinya infrastruktur di Jakarta khususnya Jakarta Timur seluruhnya mengutamanakan pejalan kaki," jelas Anies Baswedan. Dengan begitu, konsep pembangunan tersebut dapat menciptakan Kota Jakarta menjadi kota yang maju dan membuat bahagia warganya. Sekaligus memosisikan Jakarta sebagai kota global.

\section{KAJIAN LITERATUR}

\section{Open Architecture : Third Place}

Istilah place erat kaitannya dengan teori space. Jika space berarti tiga dimensi yang membentuk place, sedangkan karakter diartikan sebagai suasana dari sebuah place. Edward Relp, Prospect of place, berpendapat bahwa ada hubungan antara lanskap, pengalaman keseharian dengan faktor sosial dan ekonomi dalam pembentukan sebuah ruang. Istilah place dikaitkan dengan hubungan antara lanskap, pengalaman keseharian dengan faktor social sebagai tempat-tempat yang unik, lanskap, ruang-ruang komunal dibandingkan dengan pengalaman dan lingkungan tertentu (Larice dan Macdonad, 2007).

Pengertian Place bukanlah sesuatu yang abstrak atau sekedar berupa konsep, tetapi Place adalah sebuah fenomena kehidupan yang mengandung unsur pengalaman langsung, mempunyai arti dan merupakan sesuatu yang nyata yang didalamnya terdapat aktivitas yang terjadi terus menerus. Keberadaan Place sangatlah penting karena merupakan sumber dari sebuah identitas yang menunjukkan eksistensi individu maupun komunitas, bahkan lebih dari itu, place mempunyai hubungan yang emosional sangat dalam dan psikologi, baik itu seseorang maupun komunitas. Menurut Ray Ouldenburg, The Problem of Place In America, Istilah Third Place adalah istilah yang umum untuk menandakan tempat-tempat publik yang diadakan secara tetap, sukarela, informal untuk kegiatan informal, seperti berkumpul bersama keluarga atau teman (Larice dan Macdonad, 2007). 
Ditinjau dari sejarahnya fenomena Tempat Ketiga (Third Place) muncul pada tahun 1980 an di Amerika. Awalnya, keberadaan Tempat Ketiga tidak terlepas dari perkembangan revolusi industri yang terjadi di negara-negara Amerika yang memisahkan antara tempat tinggal dengan tempat kerja atau Kawasan industri. Dimana tempat tinggal mengidentifikasikan rumah disebut sebagai First Place sedangkan tempat kerja disebut sebagai Second Place.

Dalam perkembangannya, pemisahan antara Kawasan pemukiman dan kawasan kerja memunculkan kritik terhadap revolusi industri karena dianggap tidak manusiawi dan tidak menyediakan tempat atau kawasan rekreasi untuk para pekerja. Pembangunan pemukiman yang individual berpengaruh pada kehidupan sosial masyarakat. Dimana antar masyarakat tidak saling mengenal, meskipun dalam satu lingkungan. Lingkungan pemukiman yang terbentuk terasa sangat membosankan dan mengisolasi masyarakat. Aktivitas masyarakat khususnya remaja lebih banyak terjadi di dalam rumah dan tempat kerja yang secara menerus menimbulkan rasa bosan, namun ironisnya masyarakat tidak menemukan tempat di luar lingkungan rumah untuk berkegiatan dan berkumpul antar sesama remaja yang sebaya. Oleh karena itu dampak dari pemisahan pemukiman pada era revolusi industri adalah kebutuhan akan Tempat Ketiga (third place) guna menjembatani kehidupan dalam rumah dan aktifitas kerja dengan kegiatan informal.

Pada awalnya Tempat Ketiga (Third Place) berkonotasi buruk dan identik dengan budaya konsumtif. Istilah Third Place hanya mengarah kepada tempat-tempat hangout seperti kafe dan bar. Padahal istilah Third Place juga mengarah pada ruang-ruang terbuka kota, seperti taman kota, plaza, dan sidewalk dimana masyarakat dapat menghabiskan waktu untuk berkumpul dengan saudara atau teman-teman sambil menikmati suasana kota. Oleh Karena itu Third Place juga disebut sebagai a public meeting place (Larice dan Macdonad,2007).

Di Jepang, keberadaan ruang kota seperti jalan tidak hanya sebagai jalur kendaraan namun juga memiliki peranan sangat penting untuk membentuk sebuah Tempat. Sebagaimana Shelton (1999) menuliskan: Arsir, Volume 2, Nomor 1, Juni 201860 "The street as stage. How different Japan..you, the walker, are not the actor." Peran jalan dianggap penting, karena jalan itu sendiri merupakan aktor yang membentuk aktifitas masyarakat di ruang luar yang atraktif bukan hanya sekedar jalur tapi sebagai ruang informal, sosial dan komunal. Begitu juga dengan Sidewalk juga digunakan lebih dari sekedar jalur pejalan aki namun untuk dapat berfungsi sebagai ruang sosial bahkan ekonomi. (Shelton (1999))

\section{Creative Space}

Menurut Creative HubKit British Council Creative Economy, Creative Space adalah tempat, baik fisik atau virtual yang menyatukan komunitas atau pun orang-orang kreatif yang didalamnya memberi ruang dan dukungan untuk komunitas, mengumpulkan, pengembangan bisnis, dan bidang lainnya seperti sektor kreatif, budaya dan teknologi.

Tujuan Creative Space :

a. Menyediakan fasilitas dan pelayanan untuk kegiatan dari pertemuan, diskusi, meeting sebuah organisasi hingga pelatihan keterampilan dan peluang global baik dalam kurun waktu jangka pendek ataupun jangka panjang.

b. Untuk memfasilitasi kolaborasi antar komunitas.

c. Sebagai fasilitator antara komunitas atau orang kreatif dengan Lembaga pengembangan dan institusi kreatif dan non-kreatif.

d. Sebagai media komunikasi dan memperluas jaringan.

e. Memberikan apresiasi pada komunitas atau orang yang telah berkarya dan berinovasi

Creative Space disebut dengan collectives, cooperatives, labs, incubators dan bisa bersifat statis atau dinamis/online. Beberapa jenis Creative Space yang umum dijumpai antara lain :

a. Studio : Menyediakan ruang kerja bagi individu atau kelompok kecil berupa Coworking space.

b. Network : Creative Space dengan anggota yang tersebar di beberapa sektor tertentu.

c. Online Platform : Berhubungan dengan sesama komunitas hanya melalu media online . 
d. Center: Creative space dalam skala besar yang juga menyediakan beberapa fasilitas penunjang seperti café, bar, cinema, ruang pameran, toko/shop.

e. Cluster : Creative Space yang menjadi tempat bernaung individu atau komunitas kreatif pada wilayah tempat tinggal yang sama.

f. Alternative : Creative Space yang fokus pada kegiatan dengan komunitas baru, sektor dan finansial

Creative Space juga dikelompokkan berdasarkan bentuk usahanya, antara lain :

a. Struktural : bentuk Struktural ini kemudian dibagi lagi menjadi 2 jenis yaitu Creative Space yang dibentuk atas dasar Profit /Private dan atas dasar Non-Profit/sosial.

b. Sektor : bentuk Sektor ini kemudian dibagi lagi menjadi 2 jenis yaitu Multidisciplinary Creative Space (gabungan beberapa jenis komunitas dalam satu tempat baik itu di bidang kreatif, teknologi, budaya, sosial dan bisnis) dan Creative Space Spesifik (Games Hub, Tech Hub).

c. Pelayanan : bentuk Creative Space ini menawarkan pelayanan fasilitas yang lengkap mulai dari ruangan hingga event / kegiatan.

\section{METODE}

Metode perancangan dalam proyek ini dengan cara pengamatan lapangan, pengamatan dilakukan untuk mendapatkan data mengenai kondisi tapak pada saat ini dan melakukan pemetaan tentang fasilitas sosial dan umum yang ada pada sekitar lokasi tapak serta memahami kekuatan, kelemahan, peluang dan ancaman pada tapak yang dapat mempengaruhi proyek.

\section{DISKUSI DAN HASIL}

\section{Kelurahan Cipinang Besar Selatan}

Kelurahan Cipinang Besar Selatan, Kelurahan ini terletak di Kecamatan Jatinegara, Jakarta Timur. Kelurahan ini memiliki penduduk sebesar 40.467 jiwa dan luas 1,63 km². Kelurahan ini berbatasan dengan Kelurahan Cipinang Besar Utara di sebelah utara, Kelurahan Cipinang Cempedak di sebelah barat, Kelurahan Cipinang Muara di sebelah timur, dan Kelurahan Cipinang Melayu di sebelah selatan.

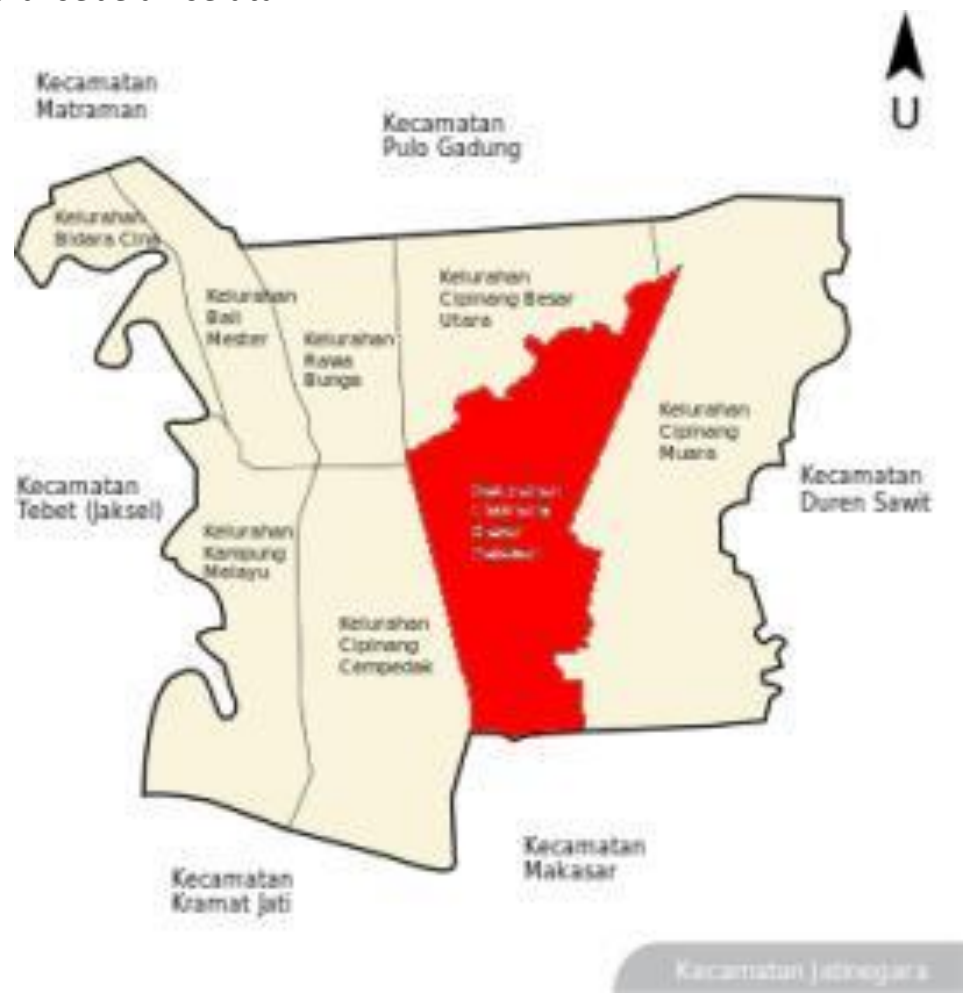

Gambar 1. Kecamatan Jatinegara

Sumber: Google dengan olahan Penulis 2019 


\section{Lokasi Tapak}

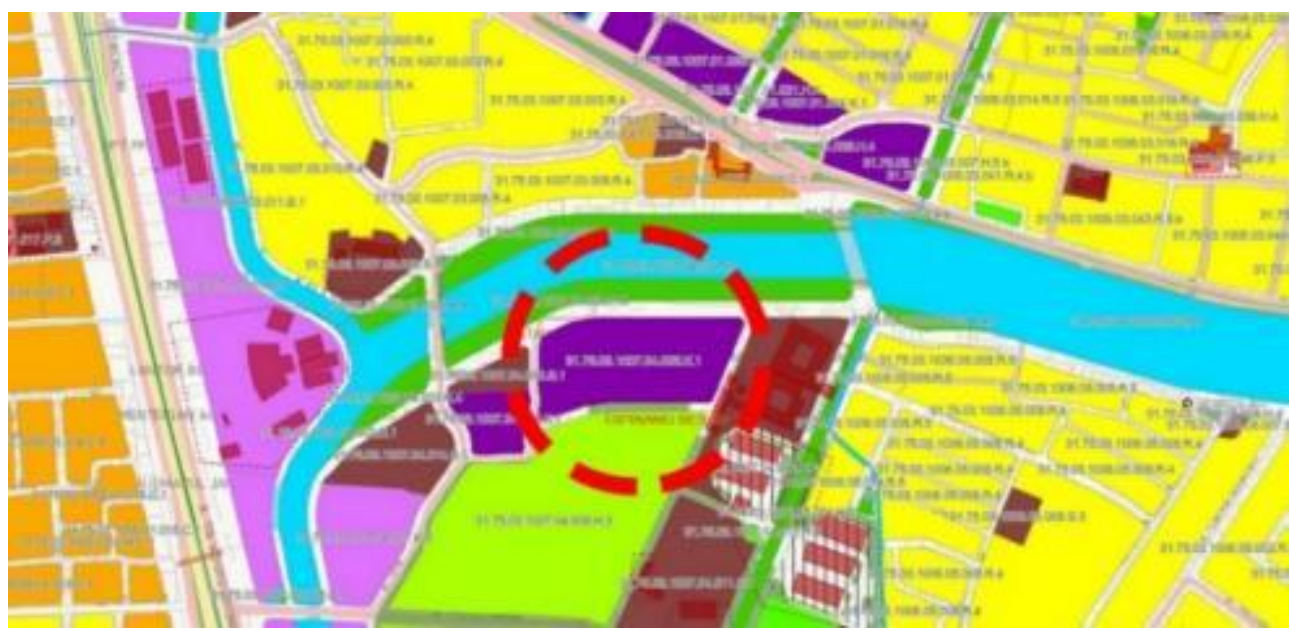

Jl. Masjid Baitul Latif

Cipinang Besar Selatan

Kecamatan Jatinegara

Kota Jakarta Timur 13410

ZONA : Zona Perkantoran, Perdagangan, dan Jasa. KDB 40, KLB 0.8, KB 2, KDH 30, KTB 55

\section{Gambar 2. Kelurahan Cipinang Besar Selatan}

Sumber: Google dengan olahan Penulis 2019

\section{Akses Tapak}

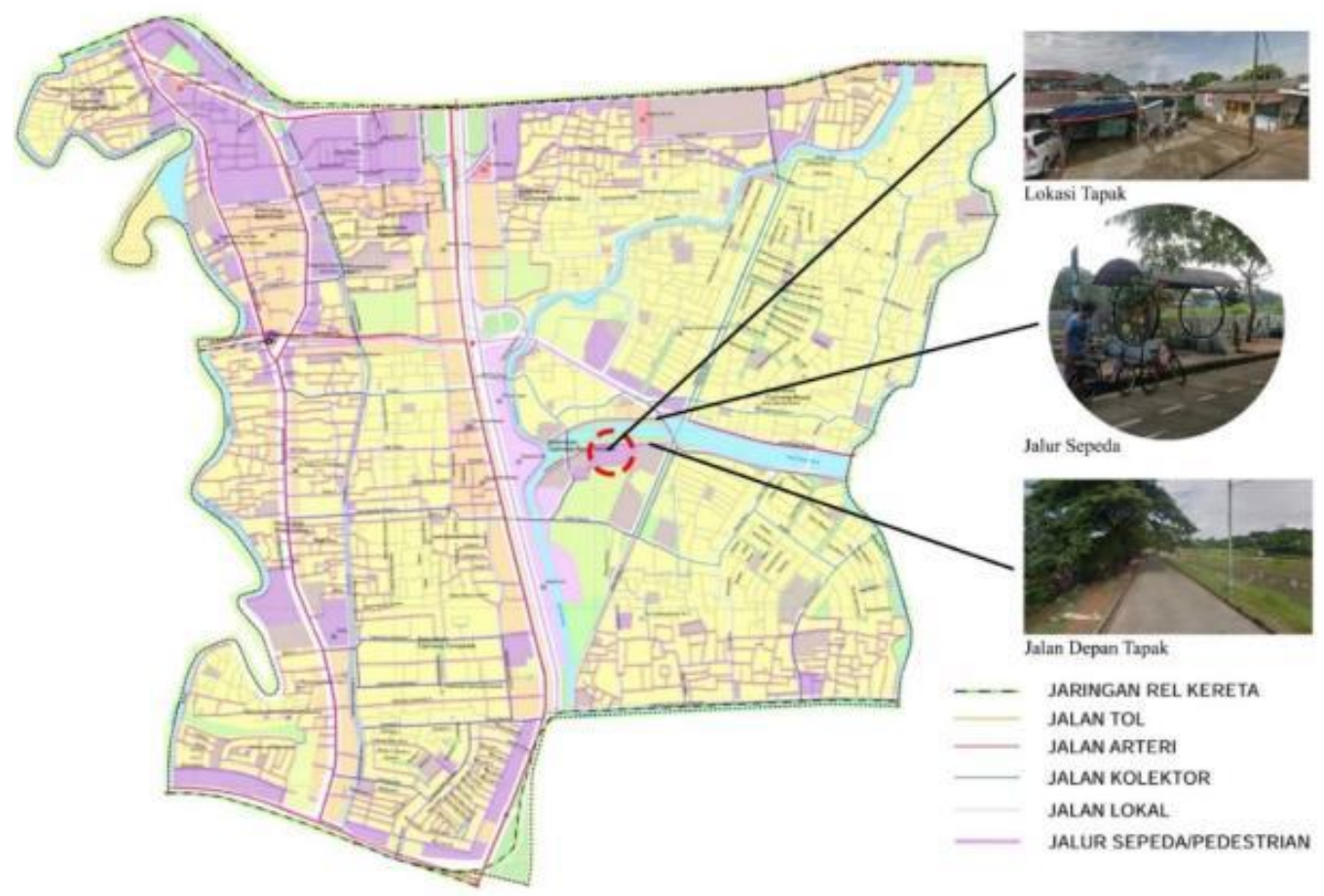

Gambar 3. Wilayah Cipinang

Sumber: Google dengan olahan Penulis 2019 
Akses menuju tapak bisa melalui jalan tol, arteri, kolektor, lokal, dan jaringan rel kereta. Pada wilayah tapak terdapat jalur bagi pengguna sepeda, dan terdapat jalur pedestrian.

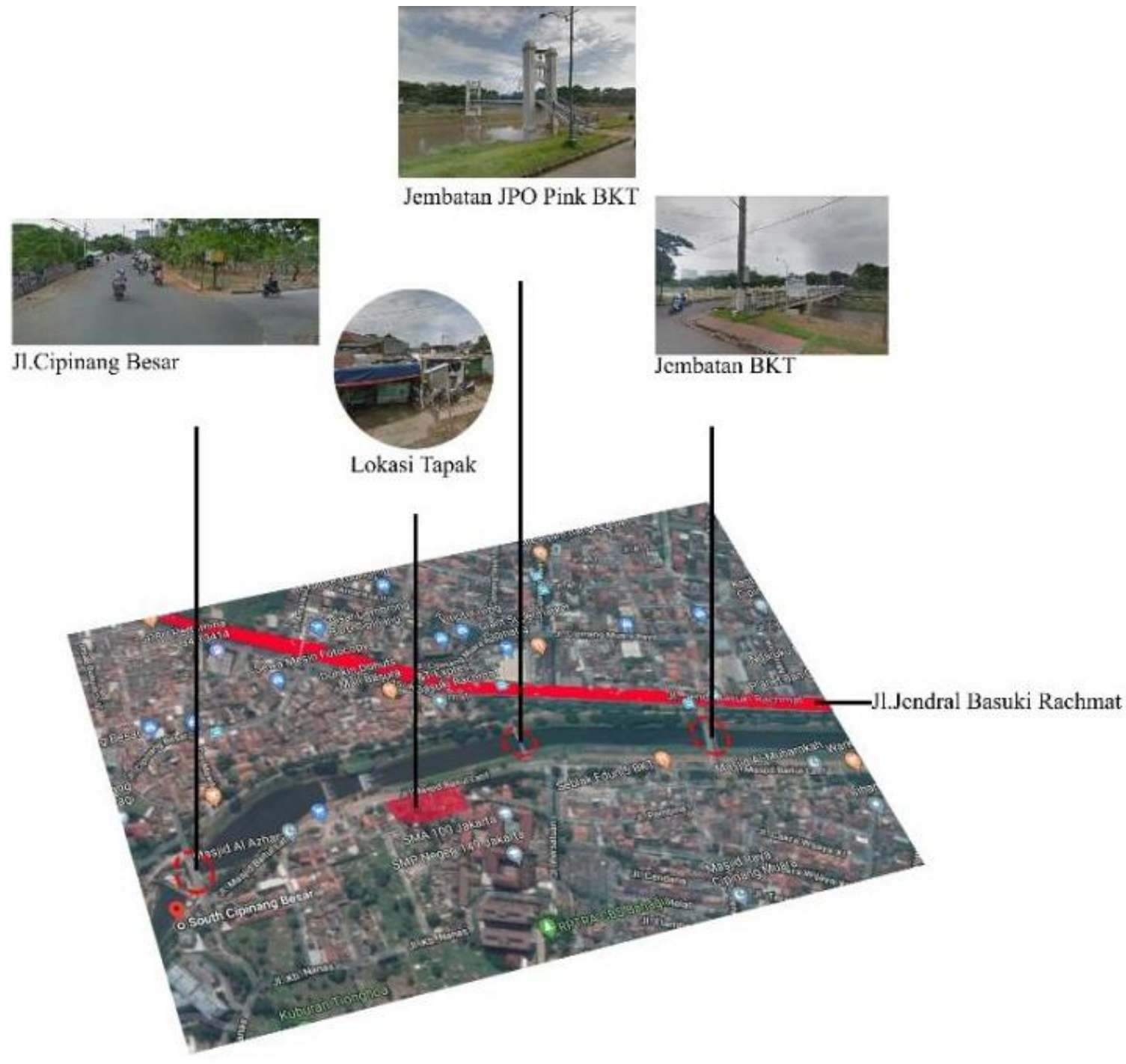

Gambar 4. Akses Menuju Tapak

Sumber: Google dengan olahan Penulis 2019

Lokasi tapak berdekatan dengan jalan arteri yaitu jalan Jendral Basuki Rachmat, untuk ke lokasi tapak bisa mengakses dari 3 jalan, yang pertama melalui jalan cipinang besar bagi kendaraan bermotor dan bisa melalui jembatan bkt. Bagi pejalan kaki untuk ke wilayah tapak bisa melalui jembatan penyeberangan orang pink BKT. 


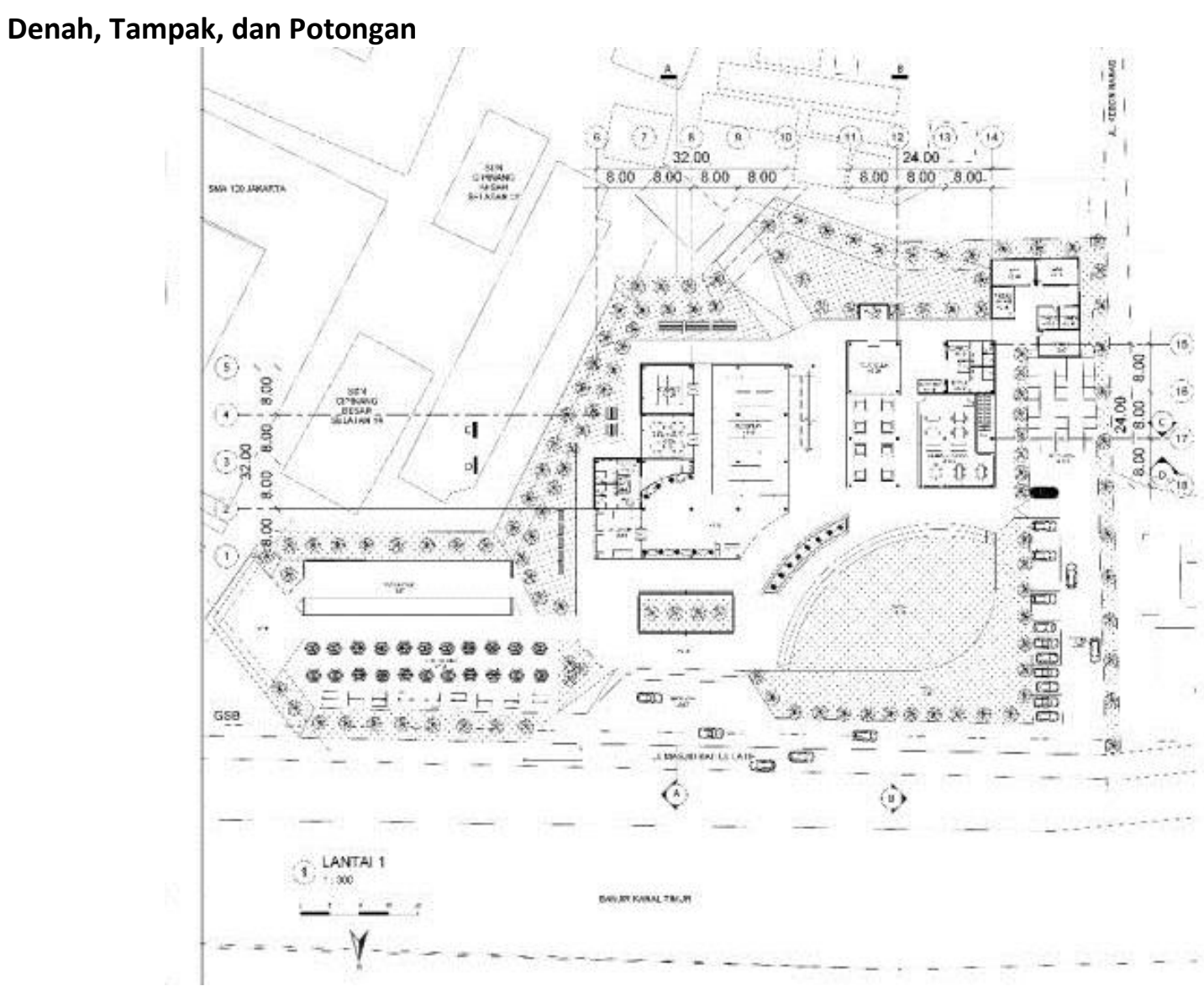

Gambar 5. Denah Lantai 1

Sumber: Penulis, 2019

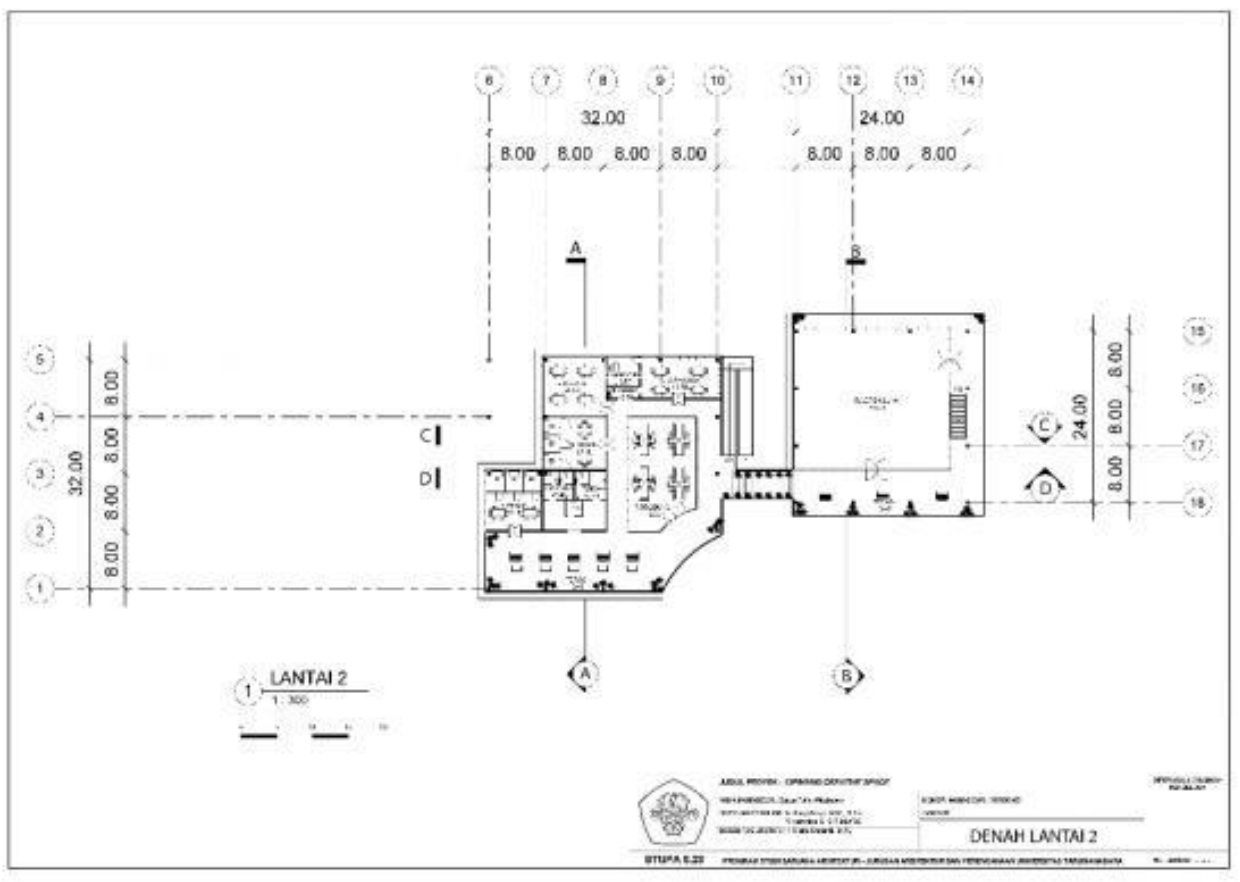

Gambar 6. Denah Lantai 2

Sumber: Penulis, 2019 


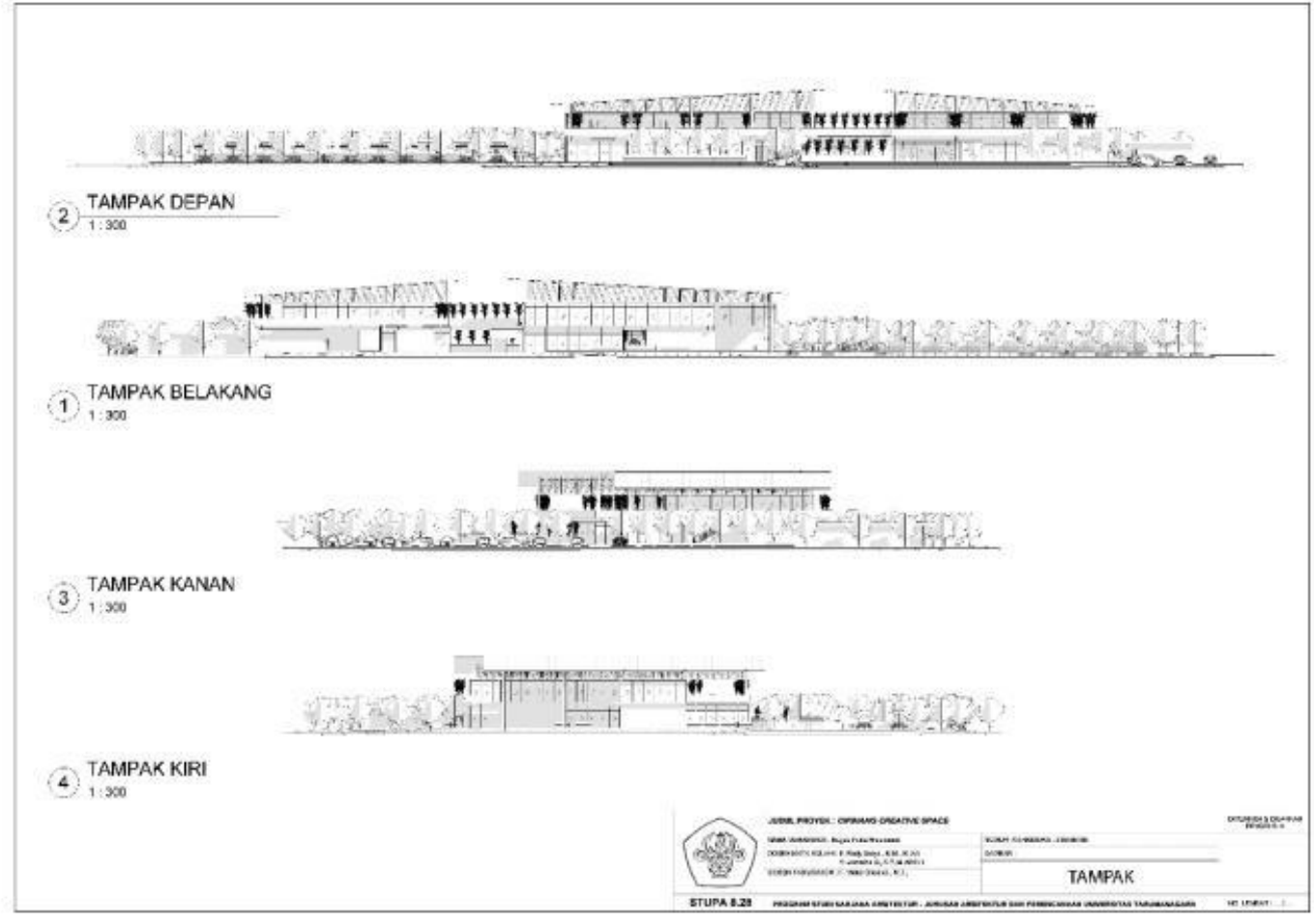

Gambar 7. Tampak

Sumber: Penulis, 2019

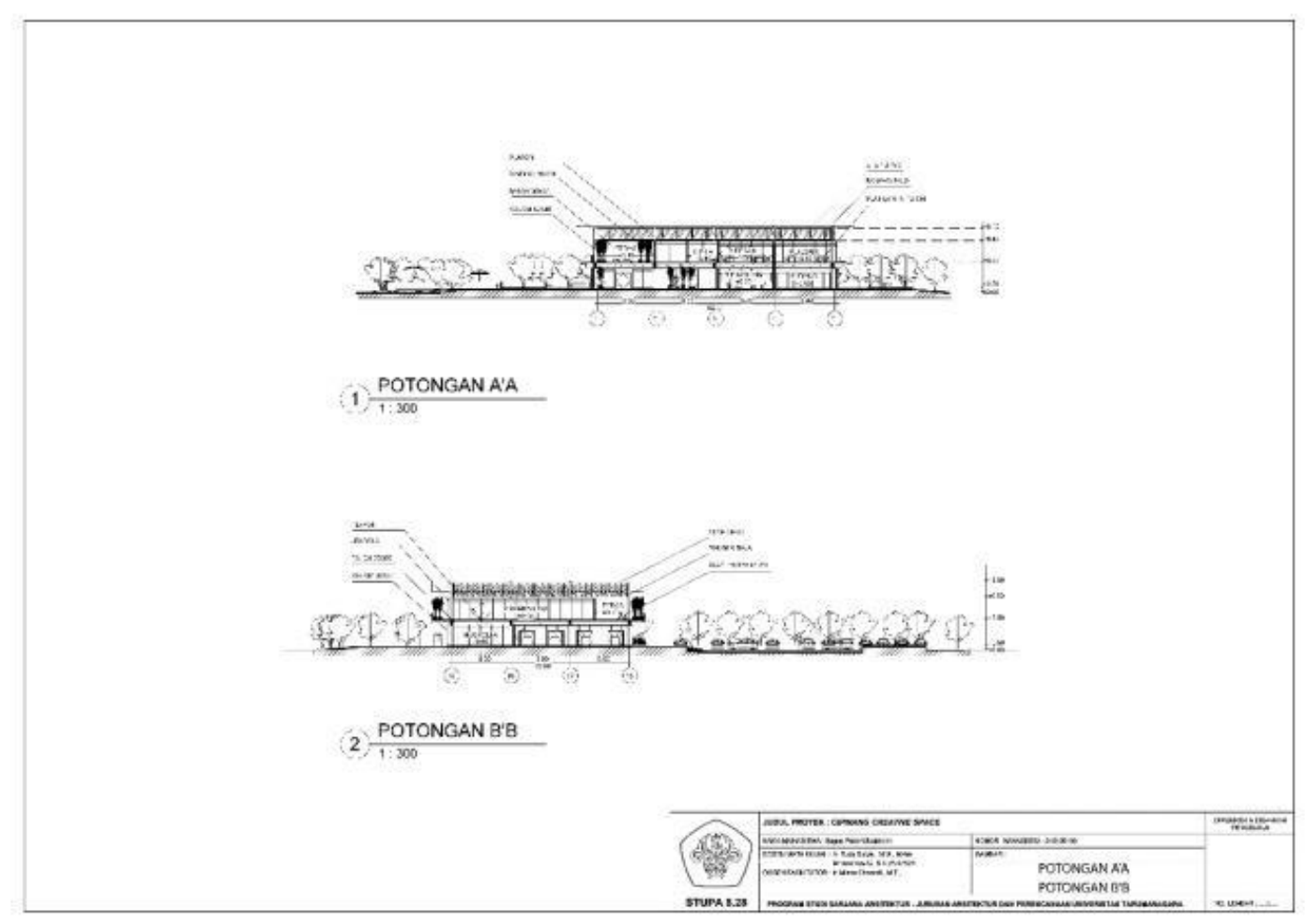

Gambar 8. Potongan

Sumber: Penulis, 2019 


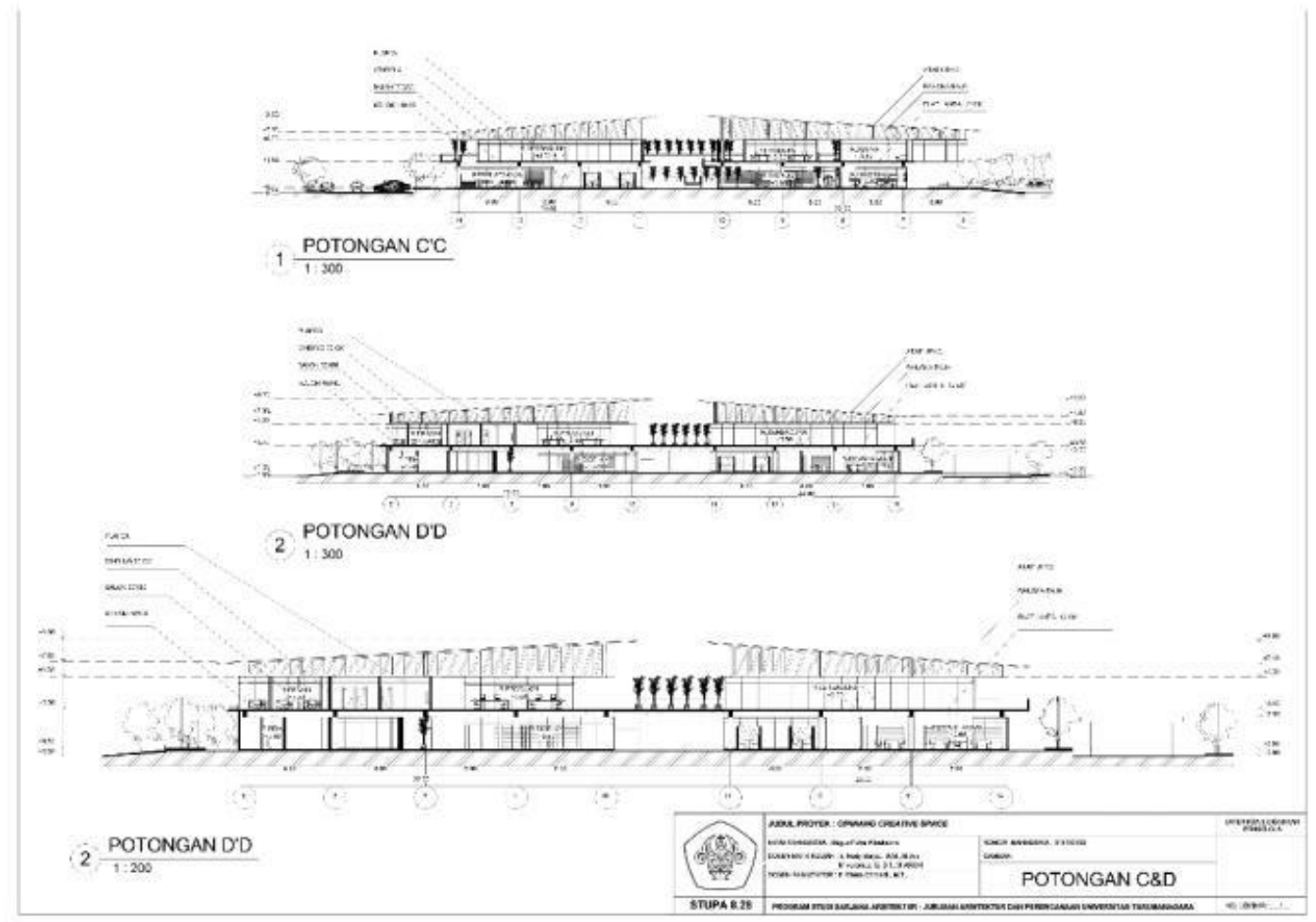

Gambar 9. Potongan

Sumber: Penulis, 2019

\section{KESIMPULAN DAN SARAN}

Indonesia tercatat sebagai penduduk yang mengalami stres dimana tingkat stres tersebut dapat meningkat jika tidak diatasi. Adanya faktor stres dari penghasilan yang rendah, dan taraf kehidupan yang tinggi. Oleh sebab itu perlu ada ruang sebagai tempat interaksi bagi seluruh kelas sosial masyarakat dan dapat menjalin perekonomian masyarakat yang baik.

Dimana pada daerah Jakarta timur berpotensi untuk meningkatkan Kawasan perekonomian dan juga ada rencana yang akan di buat tempat ketiga pada wilayah Jakarta timur oleh pemerintah. Proyek ini diharapkan dapat memfasilitasi seluruh lapisan sosial masyarakat yang dapat berkreasi, saling bertukar pikiran dan mengembangkan perekonomian

Ruang ketiga yang dirancang untuk membuat interaksi lintas kelas sosial-ekonomi. Konsep pembangunan tersebut dapat menciptakan Kota Jakarta khususnya pada Jakarta Timur menjadi kota yang maju dan membuat bahagia warganya. Berikut program - program aktivitas dan fungsi utama yang di buat untuk pengguna pada proyek creative space, diantaranya ;

- Tempat kreatif bagi seluruh lapisan masyarakat kreatif

- Ruang untuk memperlihatkan hasil karyanya

- Fasilitas pendukung seperti; taman baca, taman bermain, retail, area makan dan minum, dll

\section{REFERENSI}

British Council (2015). Creative HubKit: Made by Hubs for Emerging Hubs. London. Creativeconomy.britishcouncil.org/media/uploads/fil es/Creative_HubKit.pdf Larice, L. et.al. (2007). The Urban Design Reader, second edition, Routledge, NY Shelton, B. (1999). Learning from the Japanese City, West Meets East in Urban Design, London: E\&FN Spon 
https://timur.jakarta.go.id/v15/news/Pemerintahan/4019/wali-kota-jaktim-serap-aspirasiwarga-di-rembug-rw-cipinang-besar-selatan

https://timur.jakarta.go.id/v11/?p=potensi.wilayah

http://www.depkes.go.id/resources/download/info-terkini/hasil-riskesdas-2018.pdf

https://www.who.int/countries/idn/en/

https://www.archdaily.com/895749/dongziguan-villagers-activity-center-gad-x-line-plus-

studio

https://www.archdaily.com/801850/enabling-village

woha?ad source=search\&ad medium=search result all

https://www.archdaily.com/800497/the-commons-department-of-architecture

https://jaktimkota.bps.go.id 